\title{
Turning Points and Continuity Introducing a research project
}

\section{LENA HAMMERGREN \& WILLMAR SAUTER}

This special issue of Nordic Theatre Studies is part of a large-scale research project funded by the Swedish Research Council, initiated in 2014. In this issue, we have gathered nine articles written by both project members and invited guests with the aim of showing a combination of historiographical and thematic analyses of source material. The authors have different scholarly backgrounds; in theatre, dance, performance, literature as well as economics, and they also write about a variety of genres.

The ambition of this group of researchers has been to broaden the concept of a period, to enlarge the scope of accessible information, and to complete the narrow picture of the so-called modernist turn(s). To achieve this aim, the close study of archives was necessary. The archives provided these scholars with well-known as well as unexpected traces of the past, which were not premeditated as evidence of already established questions, but represented a free flow of information that had to be reconstructed as new and relevant historical knowledge. Historical theatre reviews, for example, were not used as sources that hold information about the specificities and qualities of a performance, but the reviewers themselves were the focus of attention. To attempt close readings of the critic's language in the manner that some articles do is quite uncommon and result in a different understanding of the so-called avant-garde and where it resides. Actor's contracts mirror the power relationships between employer and employee, whereas the particulars of the individual performer remain marginal. Private letters are not related to stage practices but to the social advancement of an actress/performer, and to questions of morale and female sexuality. Books on theatre history are scrutinized in regard to their aims and motives rather than the information they provide - why are periods established 
and how are genres defined? The pluralist view of the archive as multiverse transforms both the source material and the scholars' questions. But this has not been sufficient. Theoretical considerations complement the evidence that was brought to the fore. Traditional approaches had to be deconstructed and additional concepts had to be developed. This means a fresh view on the archives as such, unimpaired by teleological aims and hypotheses, but rather as collections of traces that become revitalized and repositioned. The archive has become a living partner in the search for a profound understanding of the past.

In our research application to the research council, we particularly stressed the importance of visiting different kinds of archives and looking at existing source material from new perspectives, as the text above reveals. From an overarching theoretical perspective the project is firmly situated within the socalled archival turn. The Western logic of the archive forces us to look at the archival remains as the only reliable point of departure for grasping our pasts and futures. However, in tandem with contemporary discourses that challenge this logic, we fully acknowledge the contingent nature of archives, understanding that the methods for collating and storing documents shape the knowledge produced. In Derridean terms, "archivization produces as much as it records the event". ' Still, it is important to acknowledge that some kind of truth claims of archival documents still exists within performance studies, which is revealed in one of the enclosed articles on autobiographies. Instead of arguing about "truth", it can be productive to follow sociologist Thomas Osborne's suggestion, to think of the archive "'as a principle of credibility"."2

Theatre/Histories are constantly rewritten. This is not necessarily an accumulative process that enlarges our knowledge, but many times new perspectives will enrich our understanding of historical events and processes. The following contributions to this special issue of Nordic Theatre Studies are not meant to substitute earlier research, but to complete and expand the views we have of the theatrical activities at the turn of the nineteenth century.

\section{References}

Derrida, Jacques. 1995. "Archive Fever: A Freudian Impression", Diacritics, vol. 25 , no. 2, 9-64.

Manoff, Marlene. 2004. "Theories of the Archive from Across the Disciplines", Libraries and the Academy, vol. 4, no. 1, 9-25.

1. Derrida 1995, 17.

2. Osborne cit. in Manoff 2004, 18. 